Dr. J. S. Buntinc (Torquay) writes: Since Christmas Torquay has had a spell of influenza, which appears to be passing away again. The present epidemic differs considerably from that of two years ago, being more like the old influenza or severe cold, but more infectious, and the catarrhal symptoms have been common: and whereas two years ago my patients were mostly males, this year a great majority of them have been females. The pain in the head has been rrontal, and not on the vertex and crush ing as before. The temperatures have been higher, with less frequent delirium and depression of spirits; the aching pains have been about the
same. I have had some excellent opportunities of watching cases from their apparent inception to recovery, and have indulged in an attack myself. The most common early symptoms were itching of the conjunc tivæ, irritation of throat and sneezing, followed in twenty-four hours with slight but increasing frontal headache, pain in the back (lumbar region), then a gradual rise of temperature to $99^{\circ}$ or $100^{\circ}$, followed at the end of forty eight hours by rapid increase of all the previous symptom with shivering, the temperature rising to $101.5^{\circ}$ or higher, sometimes to $104^{\circ}$ or $105^{\circ}$, depending more on the temperament of the patient than on the severity of the attack. The respirations and pulse did not usually follow the rise in temperature, only increasing the former follow the rise in temperature, only increasing the former 2 to 6 , the latter 10 to 20, per minute. Towards the end of seventy-two hours profuse perspiration set in, and the temperature began to fall whether medi cine had been taken or not. All the usual remedies have been tried, and those who took none except a placebo did equally well as the others. Hot sponges were found to relieve the headache better than anything
else. Pressure over lower part of spine relieved the lumbar pain. The other pressure over lower part of spine relieved the lumbar pain. The the course of five minutes. Champagne and hot drinks were found useful, and, as soon as improvement began. iron tonics. In one case where iron and quiuine was administered from the first, the temperature iron and quiuine was administered from the first, the temperature did not fall during recovery so low as usual, and there was and expectoration, which vielded to the usual remedies, there was and expectoration, which sielded to the usual remedies, there was considerable dulness and deficient respiration in the bases of some whose temparature ranged high, but, unless the breathing was hurrigd, they were left alone and soon recovered; they usually complained of a well and quickly. Two seen for the first time after pneumonia had set in made slow recoveries, and one, aged 71 , who was out during the preliminary stage, had severe tracheal catarrh, which rapidly passed down bronchi to capillaries, and death took place on third day. Some children had mumps witl their other symptoms. I know of no prophylactics. Quinine (" 6 grains a day), iron, arsenic, and every one of the mucl vaunted remedies have completely failed. Warm clothing, good food, and avoidance of chills, and unnecessary contact with sufferers affords the best tious disorder, because with ploper care it is not more dangerous than measles, with which it has many points in common, and both are dangerous if neglected. Judging from the history of previous epidemics, influenza is about played out, and will probably shortly disappear, to come back and astonish another generation of practitioners.

\section{THE EPIDEMIC OF 183 .}

DR. J. M. BRYAN (Northampton) writes: In 1883, when just finishing my hospital studies at Guy's. I had a very severe attack of influenza, then ver prevalent among the students, and iny head was so intensely bad that relt compelled to be bled from the arm to 10 ounces, by a fellow studen (Mr. Norris), and I kept my bed a few days and was very weak, and took s llines with liq. amm. acet., pot. nit., etc., and recovered very well; ver little cough. A full account of influenza is given in an early volume of Sydenham Society.

Errata.-In Mr. J. A. Francis's note on influenza. published in the BRITISH MEDICAL JOURNAL of January $30 \mathrm{th}, \mathrm{p}$. 245. "A temperature of "should read "in un complicated cases." Again. "Liq. ferri perchlor. mxv with an equal

quantity of liq. am. cit. fort.," should read "Lic. am. acet. fort." An

\section{W I T T E R RES R TS.}

$$
\text { III.-SAN REMO. }
$$

By Arthor Hill Hassall, M.D.Lond.

TнE literature of most of the better known winter resorts is now pretty extensive, yet it is far from complete; moreover some of it is marred by certain faults; the merits of some of the resorts are described in exaggerated terms, while on others undue blame is bestowed; again, occasionally statements are inadvertently made which are not in accordance with the facts. But the chief faults are those of omission rather than of commission; thus. in regard to the meteorology of most resorts, their sanitary condition and arrangements, the character of the water supply, the drainage, sewerage, and vital statistics, the information is meagre and wholly insufficient. In fact the Book of Healih Resorts has still to be written, but the materials for such a work do not yet exist in sufficient quantity.

Notwithstanding the wide gaps in our present knowledge, complaints are sometimes made that writers on climate are too minute in their descriptions, and that the fine distinctions made between one place and another are often too narrow. For example, it has been said that the general characteristics of the climate of the Riviera are so similar that any special description of the features of each of the several resorts scattered along the north shore of the Mediterranean are unnecessary. This is a most mistaken view, and those who hold it seem to forget that there are two Rivieras, an eastern and a western, the climates of which are very different, the former being mainly sedative, and the latter stimulative. The resorts of the Western Riviera again differ from each other in many important particulars; in temperature, sunshine, rainfall, humidity, exposure to winds. So great are these differences, that while one of the resorts will be found to disagree with certain people, another, not far removed, will prove quite suitable; in one the patient will be irritable and sleepless, in the other he will obtain the needed rest. There are, in some cases, marked differences even between the east and west sides of the same town.

It is clear, therefore, that in the compass of this short article I cannot give anything like a full description of San Remo as a health resort. I therefore confine myself chiefly to some details of the meteorology of the town, the results being based, for the most part, on daily observations carried on for eleven consecutive winter seasons. And even these results must be stated in the briefest possible form.

Temperature.-The mean north shade temperature of the six months' winter season, from November 1st to April 30th, was $52.63^{\circ} \mathrm{F}$, and if reckoned for the three months of the Italian winter season only-December, January, and February $-49.81^{\circ} \mathrm{F}$. The mean maximum shade temperature for the six months was $57.15^{\circ}$, and the mean minimum $46.53^{\circ}$. The freezing point in the air was only reached nine times in 11 seasons, but on the ground a mean of 15 times each season was reached; the mean temperatue on the ground was $40.69^{\circ}$. Snow fell on 6 occasions only in the 11 seasons.

Sun and Sunshine.-The mean sun heat by the naked black bulb thermometer for three seasons only was 72.20 ; the mean sun heat in vacun for 8 seasons, $109^{\circ} \mathrm{F}$. The mean number of days on which the sun shone during 9 winter seasons was 164 ; the mean duration of the sunshine 6 hours 51 minutes per day, and the mean total sunshine 1,221 hours.

Rain, Rainfall, and Relative Humidity.-The mean of 11 seasons: Days of rain, 34; hours of day rain for the whole season, 141 only; rainfall, 16 inches; relative humidity, $70.28^{\circ}$; saturation of the atmosphere being indicated by $100^{\circ}$. The highest shade temperature which the thermometer ever reached was $74.10^{\circ}$; the lowest $30.40^{\circ}$, which was, of course, at night, but on the ground the thermometer descended to $20.80^{\circ}$; these three last temperatures, however, occurred only once each during all the seasons. Many other results were arrived at besides the above in the course of the eleven seasons' observations, but space forbids any further details.

To sum up the climate of San Remo. The temperature is moderate, but owing to the increased action of the skin the sensation of cold is greater than the actual cold, and it is of cold that complaint is more frequently made than of heat. There is much sunshine, but the difference between sun and shade temperature is great. There are comparatively few days on which rain falls, and the air is for the most part dry, but not too much so. The two drawbacks of the climate are the prevalence of winds and the great difference between sun and shade temperature, rendering caution necessary. All places on the seashore are more or less windy, but the liability to wind is increased in the Riviera by the daily sea and the nightly land breezes; then the coast suffers at times from the mistral-a north-west wind which blows occasionally with great violence; it is most felt at Hyères and Cannes, and less so in the places lying more to the east. San Remo therefore suffers much less from this wind than do the other towns on its west side.

The water supply is excellent and abundant. Typhoid fever may be said to be unknown among the visitors, although occasionally a case is met with arising from infection caught elsewhere. The sanitary condition of San Remo will bear favourable comparison with that of most of the other towns of the Riviera; at the same time, there is much room for improvement, which the mission of Dr. Wendt may help materially to bring about.

The General Association of Paris Students, fired by the example of the sister association at Montpellier, has determined to build a home for itself. The estimated cost is one million francs $(£ 40,000)$. 